\title{
Reconstruction of Postgraduate Education Teacher-Student Relationship from the View of Postmodern
}

\author{
Qiang Zeng, Naizhu Huang* \\ Institute of continuing education, XiangNan University, Chenzhou, hunan,china,423000 \\ huangnzh@163.com
}

Keywords: graduate student; postgraduate education; teacher-student relationship; postmodernism

\begin{abstract}
The teacher-student relationship in traditional postgraduate education is a kind interpersonal relationship constructed by the paradigm of "object" on the basis of epistemology and determinism. This kind of teacher-student relationship based on subject-object binary opposition thinking mode is shown with the characteristics of strong controllability, transaction and employability, which seriously affects the students' mental health and perfect personality, and should be given with criticism and deconstruction. The constructed teacher-student relationship in postgraduate education from the view of postmodern is a new kind of interpersonal relationship, which is based on the ontology and life theory with the connotation of axiology and creationism, and the conversion of "Human being is end". This teacher-student relationship based on the concept of non centralization, irrationality and uncertainty of postmodernism, which essentially is a kind of relationship of "you and I" with "concern" as the core, thus embodying the essence of education, that is "Human being is the end".
\end{abstract}

\section{INTRODUCTION}

Graduate education is to cultivate the high-level professionals engaged in scientific research, teaching, management with spirit of innovation. As an important interpersonal relationship in graduate education, the nature of teacher-student relationship not only reflects the degree of social civilization, but also affects the quality of postgraduate education. With the continuous development of market economy, utilitarian values have lead to more and more modern people to pursue the maximization of the interests, resulting in more and more utilitarian men, who like interests more than virtue and like vulgar more than great value. Its reflection in postgraduate education is that the teacher-student relationship becomes more and more utilitarian and vulgar, while the teacher-student communication becomes more and more superficial and insipid, which results that the cultural heritage of the teacher-student relationship continues to wither, showing the characteristics of "Desertification". It is more and more urgent and necessary to construct a free and democratic teacher-student relationship with rich cultural heritage in order to make a better future for human beings and a poetic education life.

Jaspers said: "the principles of education is to guide the source and the foundation of the human soul awakening through the whole culture of the existing world, while instead of guiding the stuffs derived from the original and the mediocre knowledge (except ability, language, memory contents used as education basis)" (Jaspers, 1991) . This kind of education is essentially the liberal education based on people to highlight the self liberation of people and break the "materialization" and "enslavement" state of people. Unfortunately, the postgraduate education in our country isn't shown with the characteristics of freedom and liberation, and the autocratic characteristics and the "materialization" phenomenon of the teacher-student relationship are more and more serious, thus the construction of a new teacher-student relationship must be based on the criticism and deconstruction of the traditional teacher-student relationship. 


\section{CHARACTERISTICS AND DISADVANTAGES OF TEACHER-STUDENT RELATIONSHIP IN TRADITIONAL POSTGRADUATE EDUCATION}

The teacher-student relationship in traditional postgraduate education is a kind interpersonal relationship constructed by the paradigm of "object" on the basis of epistemology and determinism. Educators who holds this view have a long history, for example, the great educator Comenius proposed that" the right order of teaching should be borrowed from the nature without any obstacle", which was the concept of invariant order of pan naturalism to dominate the teacher-student relationship toward determinism; Herbart belonged to the traditional education school was an advocate of the teacher-student relationship based on determinism, while although he was influenced by Kant's idea that Human being is end" and put forward the idea that "moral" is the highest purpose of education, but in teaching practice, his "purpose and means" were seriously separated and lead to the teacher-student relationship heading for the autocratic position; what is more, the former Soviet Union scholar Kairov proposed to ensure that teachers decide everything in the form of "legal", trying to replace "the ethical relationship" between teachers and students with "legal relationship". The teacher-student relationship in traditional postgraduate education is the product of the subject-object binary opposition cognitive centralism. After the absolute domination of the world by instrumental reason originated from Descartes through Hagel to reach the peak, Kant's meaningful practical rationality or value rationality was gradually declining, and people really became into the "special machine" proposed by La Mettrie, while education became to create "labor power", "anthropopithecus" processing factory, and continuously reproduced large quantities of "single person". The students were used as the object of the subject-object binary opposition cognitive centralism, which not only morally implied humiliation and contempt, but also treated the living students as "objects", so the characteristics and disadvantages of the relationship between teachers and students are mainly as follows.

\subsection{Controllability}

The teacher-student relationship in traditional postgraduate education influenced by the Confucian culture and the constraints of graduate enrollment system, tutor selection system, two-way selection system, tutor responsibility system, graduate degree granting system and others, is shown with the strong controllability of teachers to students, which makes the teacher-student relationship become into a relationship of "I and he": that is to say, "I " always try to regard other people as an object, a stuff, some means to make myself as the subject. This teacher-student relationship has deviated far from the value orientation of "Human being is end", which resulted in the alienation of teacher-student relationship and the teacher-student relationship with rich connotation in the process of education was deconstructed into the people-material relationship, namely, the relationship with separation of dominant subject and dominated object. As a result, the graduate students lost their independence and autonomy in learning and were completely controlled by tutors, while their critical consciousness and independent personality can not be formed.

\subsection{Transaction}

The teacher-student relationship in traditional postgraduate education influenced by the bad social environment is shown with a strong transaction between teachers and students, for example, graduate students seek illegitimate benefits in the entrance examination, paper publication, study abroad, graduation employment, etc. in forms of money or sex bribery and other ways. This kind of teacher-student relationship is an inter-fact relationship in essence, which reflects the naked or hypocritical whitewashed interests. Strictly speaking, teacher has specific "occupation" and "function" status, and there is indeed a relationship of actual fact between teachers and students, but they should not allow the inter-fact relationship to be dominated. Teachers should consciously dilute their functional identity and let themselves appear with a personality image, thus the teacher-student relationship is more close to the essence of education. However, the reality is that the inter-fact relationship during the communication between teachers and students wasn't weakened but occupied the mainstream, what more serious is that, the teacher-student relationship in some colleges and universities has become a naked interests exchange relationship between 
"buyer" and "seller". Jaspers said, "Education is the person-to-person spirit communication activities between subjects", which is a powerful attack on the inter-fact relationship between teachers and students. Certainly, we can not completely get rid of the inter-fact relationship between teachers and students, but we should strictly limit its range, and resolutely resist and abandon the behaviors that result in the interest-oriented, market-oriented and vulgarized relationship between teacher and students, thus returning the purity and the nobility to the teacher-student relationship.

\subsection{Employability}

The teacher-student relationship in traditional postgraduate education influenced by the imperfect market economy is shown with the strong employability of teachers to students, and some graduate students almost become the cheap senior labor of the teacher. It is no wonder that many graduate students called their teacher "boss", because graduate students participated in their tutors' scientific research project and got certain reward. Because of the economic relationship between teachers and students beyond the teaching relationship, the employment characteristics of the teacher-student relationship are performed obviously. In recent years, many incidents of teacher-student relationship alienation have been founding in newspapers, such as " the tutor for PHD students in Shanghai Jiaotong University was ousted by graduate students ", " the tutor for PHD students in Xiamen University was complained by graduate students because of academic plagiarism "," the incident happened to Gan Dehuai for the doctoral examination of Beijing University ", etc., which were happened because of the moral risks caused by the employment relationship between teachers and students.

\section{CONSTRUCTION OF TEACHER-STUDENT RELATIONSHIP IN POSTGRADUATE EDUCATION FROM THE VIEW OF POSTMODERN}

\subsection{Harmonious Characteristics of Teacher-Student Relationship in Postgraduate Education}

Postgraduate education in our country is to cultivate high-level academic talents. The teacher-student relationship in postgraduate education is a kind of harmonious relationship including equal communication, living in peace, caring for each other, learning from each other and influencing each other with characteristics of personality, freedom and transcendence. This harmonious relationship between teachers and students must have three elements: The first is sincerity that the teacher-student relationship must be truthful with honest thoughts and feelings, while do not hide their feelings, do not cover up their own shortcomings, and teachers and students express the instant emotions and attitudes heartily; the second is respect that teachers should fully respect students and recognize each student as an independent individual of his own value, while in the process of teaching, teachers should be good at listening to the opinions of students, pay attention to students' emotion, appreciate the advantages of students, be tolerant of their shortcomings, maintain their dignity and hobbies, and believe that students can make choices and decisions by themselves; the third is understanding that you try to understand others as we should if we were in their place, which belongs to empathic understanding that is understanding others from the point view of others.

\subsection{Basic Idea of Postmodern Educational Thought}

Postmodern educational thought is a kind of educational trends formed in the process of profound reflection and criticism of educational modernity. The postmodern educational thoughts holds that the rationalism is the main feature of modern education, whose specific performances are shown as rationalism centralization and individualism centrality in education, while the reflection on the teacher-student relationship in postgraduate education is the centralism and unlimited authority of tutor as well as the absolute control of students. On the basis of firmly being opposed to the rational authority, the postmodern educational thought advocates the characteristics of decentralization, irrationality and uncertainty.

\subsubsection{Decentralization}

Decentralization is the deconstruction of subjectivity and the digestion of the subject-object binary opposition thought. Philosopher Derrida said: "deconstruction has always been the 
confrontation with illegitimate dogma, authority and hegemony."(Derrida,2001) Because of the existence of binary opposition, it is necessary to have a center and consider that one element in binary opposition is more important and preferential than the other one. For example, in the relationship between teachers and students, it is necessary to believe that teachers are in a more important and preferential central position, holding all the fate of students. Postmodernism is firmly opposed to "centralism" and "self centeredness", and insists that individualism is the source of various problems in human society. They are based on the overall interests of mankind, advocates to abandon individualism, eliminate people-I opposition, regarding human being as the relative existence that everyone is in the relationship with others and individuals can be understood only in the relationship between the people, emphasizing the internal, essential and constitutive relationship between the people, which has become an important feature of postmodernism: Firstly, the replacement of central subject form with communication subject form is advocated. It is thought that "dialogue" is a kind of interpersonal process, which overthrows the cognitive subject in central position through communication and advocates equal communication relationship between different observers and knower. It is thought that the real dialogue always contains partnership and cooperation; secondly, it refers to the transcendence of patriarchy and the protection of feminism. Postmodernism requires transcendence of gender and modern single male spirit to establish a kind of interpersonal relationship of mutual respect and responsibility between male and female by actively cooperating with feminism; thirdly, it refers to the condemnation of nationalism and militarism.

\subsubsection{Irrationality}

Postmodernism believes that the spread of reason caused the present predicament of human. Therefore, it is necessary to criticize, deny and deconstruct rationalism. Irrationality advocated by postmodernism is opposed to the absoluteness of any concept, category or structure and strongly emphasizes the importance of "faith", "difference" and "game", which is different from Schopenhauer, Nitzsch et al., who deliberately sought a irrational entity. In particular, the performances of irrational features of postmodernism are as follows: The first is the irrational interpretation of truth. As for the question of truth, the postmodernist changed the traditional understanding and thought that truth is not an innate strict form of existence, but an artifact. Pascal even believed that truth is true, not truth itself, but our "faith", thus the concept of truth was completely driven into the irrational world; the second is to make reason deny itself in rational operation. The influence of Deconstructionist Derrida made strategy that "only operation without any judgment "to get rid of metaphysics. In his view, only "differance" was most suitable for strategic thinking, because differance only was performed as negative, while "differance" in its special way was more "old" than ontological difference or the truth of existence; the third is to make the reason show game play. Postmodernist thinkers consciously made the process in the continuous deconstruction and the flowing game state, while "deconstruction" theory called by the postmodern philosophers is to ask all people to treat all the theories as games without believing the truth of theory; the fourth is to reconstruct the irrational subject. They suspected the conscious, coherent and organized subject, for example, Touraina claimed that subject had positive performance in emotion, politics and mind, while Griffin believed that the subject was the existence of "creativity" and a kind of "creative" image; the fifth is against the modern theory or the theory as the center. The postmodernist of skepticism argued that modern theory assumed an epistemological reality, which did not actually exist. In their view, the theory was hidden, distorted and blurred. The postmodernists of positive theory abandoned the theory as the center, and replaced with the "ordinary life of ordinary people" and local narration.

\subsubsection{Uncertainty}

The uncertainty characteristics of postmodernism are mainly performed as that they are opposed to universality or identity and praise highly about free games, diversity, pluralism and the subject with uncertainty. Firstly, the post modernism pays attention to the unique thing and the thing which cannot be repeated, rather than the general thing and the thing which appears repeatedly. Secondly, the issue on pluralism in methodology or the way of thinking is put forward. Thirdly, it is advocated 
to use "emergent subject", "subject of process" and "creative subject" to replace the modern subject of universality, namely, the advocation on a kind of subject with uncertainty.

\section{BASIC IDEAS OF RECONSTRUCTION OF NEW TEACHER-STUDENT RELATIONSHIP IN POSTGRADUATE EDUCATION BY POSTMODERNISM}

From the view of postmodern, on the basis of firmly abandoning epistemology and determinism, the construction of teacher-student relationship in postgraduate education guided by the concepts of "decentralization", "irrationality" and "uncertainty" proposed the establishment of new teacher-student relationship based on ontology and life theory with the connotation of axiology and creationism, and the conversion of "Human being is end". This new type of teacher-student relationship is no longer the inter-fact relationship, but the interpersonal relationship, which refers to the relationship that the living people meet and get along with each other with the essence of "not matter for matter, but person to person" (Zhao, 1994). In the Spring and Autumn period when Chinese feudal system has not yet formed, the harmonious and warm teacher-student relationship between Confucius who was his students' friend and master and his students with the characteristics of democratic equality is the historical reflection of this new teacher-student relationship. The core of this new teacher-student relationship is the "concern" for people. Foucault, a French philosopher of postmodernism, almost abandoned power issue in the late period, but focused on the ethical subject and put forward "concern yourself" instead of "know yourself"; Socrates described himself as the master of "concern yourself" in his trial and denounced that the judges didn't concern their own " wisdom, truth and perfection of the mind". In fact, "concern yourself" is different from immoral behaviors, like "selfish", etc. Aristotle as the rationalism master has incisively discussed about this issue and he thought "concern yourself" contained the real ethics, while "concern yourself" is not a narrow "monadological" position, but directly pointed to the ethics that respect others is to respect yourself. Heidegger, a philosophy master of existentialist, also believed that "concern" is the most important and fundamental issue in the communication between people. "Learning to care" proposed by UNESCO is the strong evidence of the idea of "caring for yourself" in a sense. Education is the humanized field with love. When criticizing the education ignoring human feelings, Jaspers pointed out: "the current education itself has become more and more lack of love, resulting in the activity without love -- but the educational work are carried out in mechanical, cold, dead way. Therefore, how to integrate the cultural function of education with the casting function on soul becomes the source of people's reflection on education. The essence of "humanistic" education proposition put forward by Rodgers, a humanistic educator, lied in the establishment of new teacher-student relationship based on "concern". Although the "cooperative education" in former Soviet Union didn't discuss the teacher-student relationship from the perspective of ontology and life theory, but it proposed the free learning without mandatory to cultivate the integrity of personality, which is a kind of great theoretical consciousness and courage of reflection for the removal of all the drawbacks of Kailov's pedagogy and the ethical relationship with respect of returning the "legal relation" to the teacher-student relationship as the connotation.

The teacher-student relationship with "concern" as the core is the relationship between "you and I" in essence. Descartes in France believed that the relationship between people is always the relationship between thinkers and between subjects (Hao, 2005). Husserl believed that everyone is a self, but these "self" have a common world. Self of me and self of him form a community because having a common world, resulting in the transition of single subjectivity to inter subjectivity (Lu, 2007). Jaspers in Germany introduced the inter subjectivity into the field of pedagogy. Buber and Levina further transformed the inter subjectivity into the relationship between "you and I". Buber found that the relationship between "you and I" is the encounter between two people as pure human beings -- which excludes the relationship of mutual oppression-- which means the coexistence of freedom, that is the communication of equal personalities. Levina further strengthened the meaning of "you": The emergence of "you" means the emergence of a sense of responsibility. Therefore, the relationship between "you and I" is the basis of all love, friendship, and sense of responsibility, which is the respect of another personality and the recognition of free existence. Because of this, the 
essence of the relationship between "you and I" lies in the expression of mutual concern between people, and that is to treat people as purpose. The teacher-student relationship between "you and I" refers to that the fates of people in communication are closely interlinked. People are in the relationship with completely mutual equality to open their minds and bodies and this relationship based on concern, respect, responsibility, democracy with "adult" as foundation embodies the true connotation of education, namely, "Human being is end ".

Postmodernists are strongly advocating the establishment of "I and you" relationship between people. Bubear once said, "the development of a person depends on the development of all the directly and indirectly communicated people (Joseph.qi ya., 1987)." Everyone is growing and developing in social communication between people, while if education is without teacher-student interaction, both teachers and students would lose the basis and foundation of existence, more importantly, both teachers and students can not obtain growth and development without mentioning the sublimation and the transcendence of value. The post modernist thought the understanding of "I and you" relationship with inter subjectivity involves the following aspects(R.S.,Wang,1994): Firstly, inter subjectivity means common mutual understanding, not only self of me but also self of "him"; secondly, it means that the mutual recognition by both sides in communication, recognizing that self of him has the same status and rights with self of me; thirdly, it means the equality of personality and opportunity of both sides in communication, and the opposition of mandatory and oppression; fourthly, it means the obedience of common rules that both parties in communication must abide by the agreed specifications; fifthly, it means the harmony between subject and nature. The relationship between teachers and students, as a special kind of interpersonal relationship, should also be a pure relationship between "I and you". This relationship is reflected in two aspects: the first is the interaction between the two subjects. All teaching activities are achieved in the process of interaction between teachers and students without object, controlling and the problem of imposing one's will on the other; the second is that the teacher-student relationship is not only the background of education to provide the conditions for the implementation of education and teaching, but also the manifestation of educational activities, that is to say, the relationship between teachers and students is the manifestation mode of education itself and itself has educative nature-- the cultivation of spirit. In this "I and you" relationship between subjects, teachers and students have the unique spiritual integrity, and everyone is an individual with independent spirit and complete mental outlook; at the same time, they are also with mutual interaction, mutual absorption and mutual creation. Therefore, this relationship includes not only the movement and the growth of spirit, but also the recognition and the acceptance of the uniqueness of individual. In the view of postmodernism, the teacher-student relationship is not a mystical relationship between teachers and students, and not a relationship created deliberately of control and anti-control, while the teacher-student relationship is a kind of life relationship, regardless of teachers or students. "In perfect relationship between teachers and students, both teachers and students obtain new experience in understanding and communication of spirit, and the spiritual expansion, while the spiritual communication between the two sides is constructed by the mutual acceptance of the two sides when interacting, thus teachers can become the guide of the students' development and education is a complete education in the educational relationship between teachers and students." The relationship between "you and I" is the existence of "we", while "we" is equal and is a kind of digestion of power. In the process of education, democratic equality reflects the mutual respect between teachers and students. Teachers should learn to listen, pay attention to the inner world of students and encourage students to speak in order to eliminate the psychological tension between teachers and students. Teachers' intention of active listening is not to confirm the correctness of a certain position or idea and not to become the "referee", but to link the students' different views together and actively build a dialogue situation so that the two sides in this situation can obtain knowledge from each other's experience and the spiritual lesson. It is necessary to point out that the "you and I" relationship between teachers and students does not mean to deny the differences in roles and functions between teachers and students, does not mean that the roles of teachers and students in education are completely same, and also does not mean the loss of their unique positions 
and differences between teachers and students. On the contrary, postmodernism educators believed that the differences in age, experience, knowledge and social maturity and other aspects are one of the objective basis that the activities of education and teaching could exist in human society. If teachers are the same with students in all aspects or have the same level with students, the dialogue between teachers and students can only be in low level. The activities of education and teaching could be carried out between teachers and students just because of their differences, which are also used to distinguish roles and functions between "teachers" and "students". The relationship between teachers and students, as we say, is that teachers and students are equal in value and dignity as human beings. According to the understanding of postmodernism, the people with various grades and ranks do not exist in education and there is no problem about control and anti-control, while everyone is in the "you and I" relationship. This kind of equality is the supreme principle to measure and regulate the communication between teachers and students, and it is also the starting point of understanding and dealing with the relationship between teachers and students. It is just in this kind of "you and I" relationship between subjects, where teachers and students could experience the life growth together.

\section{ACKNOWLEDGMENTS}

College Teaching Reform Research Project of Hunan in 2015 "Research on Theory and Practice of "Double Qualified Teachers" Construction in Local Colleges and Universities Based on Cooperation between Universities and Enterprises" X.J.T. [2015] No.291; College Teaching Reform Project of Hunan in 2016 "Practical Research on Teaching Quality Monitoring in Adult Higher Education Correspondence Station of XiangNan University" X.J.T. [2016] No.400.

\section{REFERENCES}

[1] Jaspers, 1991. What is education. translated by jin Zhou. life, reading and new knowledge: Beijing, pp.3,

[2] Derrida, 2001.Writing and difference. the joint publishing company LTD: Beijing.

[3] Zhao, T.Y., 1994. May life. The joint publishing company LTD: Beijing.

[4] Hao, W.W., 2005. Philosophy foundation and practice strategies of the construction of teachers and students inter subjectivity. Journal of Beijing normal university (social science edition).

[5] Lu, J., 2007. People's understanding: The foundation of moral education - thinking of the contemporary transformation of moral education of. Education research.

[6] Joseph. Q.Y., 1987. French trend in the 20th century. the commercial press: Beijing.

[7] Wang, R.S., 1994. Introduction to social philosophy. people's publishing house: Beijing. 